\title{
OPTIMAL PLACEMENT OF DISTRIBUTED POWER-FLOW CONTROLLER FOR LOSS REDUCTION USING FIREFLY AND GENETIC ALGORITHM
}

\author{
P.Ramesh ${ }^{1}$, M.Damodara Reddy ${ }^{2}$ \\ ${ }^{1}$ Research Scholor, Department of EEE, SVU College of Engineering, S V University, Tirupati, A.P., India. \\ ${ }^{2}$ Professor\&Head, Department of EEE, SVU College of Engineering, S V University, Tirupati, A.P., India. \\ pramesheee@yahoo.co.in
}

\begin{abstract}
The aim of this paper is to reduce power loss and improve the voltage profiles in an electrical system in optimal manner. The flexible AC transmission system (FACTS) device such as Distributed power flow controller (DPFC) can strongly improve the different parameters in a power system. DPFC can be used to reduce line losses and increase voltage profiles. The optimized allocation of FACTS devices is an important issue, so the Voltage stability index (L-index) has been used in order to place UPFC in power system. The advantage of the L-index is to accelerate the optimization process. After placing the DPFC, Firefly optimization method is used for finding the rating of DPFC. The results obtained using Firefly optimization method is compared with Genetic Algorithm. To show the validity of the proposed techniques and for comparison purposes, simulation carried out on an IEEE-14 Bus and IEEE- 30 Bus test system for different loading conditions.
\end{abstract}

Keywords: Distributed power flow controllers (DPFC), Optimized Placement, Voltage stability index (L-index), Firefly optimization method, Genetic algorithm.

\section{INTRODUCTION}

Most large power system blackouts, which occurred worldwide over the last twenty years, are caused by heavily stressed system with large amount of real and reactive power demand and low voltage condition. When the voltages at the system buses are low, the losses will also be increased. This study is devoted to develop a technique for improving the voltage and minimizing the loss and hence eliminate voltage instability in a power system [1]. Thyristor-Controlled Series Capacitors (TCSC), Thyristor Controlled Phase Shifting Transformer (TCPST) and Static Var Compensator (SVC) can maintain voltage in the power system as well as, can control the active power through a transmission line [2,].

Distributed Power Flow Controller (UPFC) is a versatile FACTS device which can independently or simultaneously control the active power, the reactive power, and the bus voltage to which it is connected [2]. Dr. Xin-She Yang [12] have presented Firefly algorithm is to determine the parameters of FACTS devices. In this paper, an approach to find the optimal location of DPFC by using Voltage stability index (L-index) to improve the load ability of the lines, minimize the total losses and improve the voltage profiles using Firefly optimization is presented. The results are compared with the GA optimization. Testing of the proposed approach is carried out on IEEE 14 and IEEE 30bus system [14].

\section{DPFC MODEL}

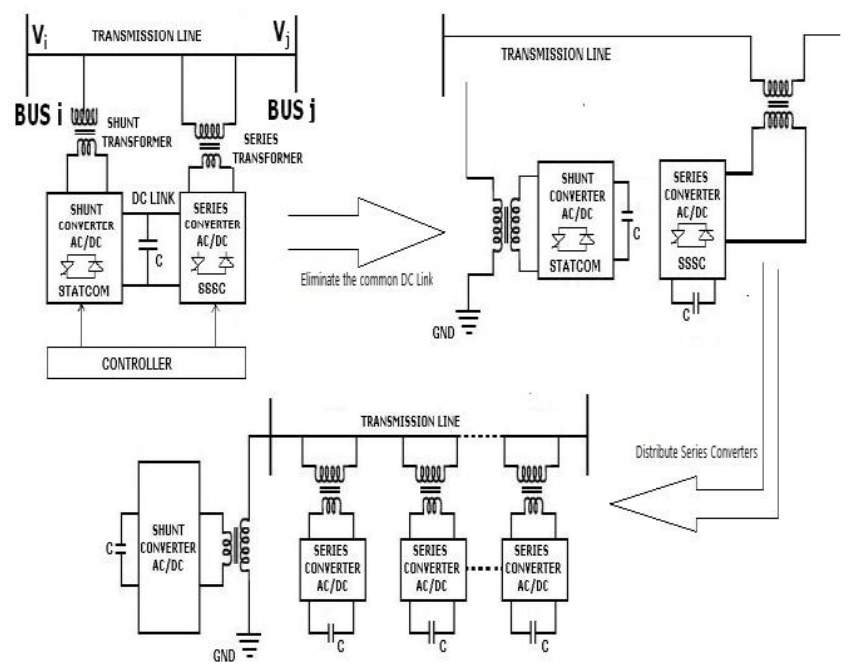

Fig.1: DPFC schematic diagram

The flow chart for DPFC is shown in Fig.1 Similar as the UPFC, the DPFC consists of shunt and series connected converters. The shunt converter is similar as a STATCOM, while the series converter [2] [11] employs the Distributed Static series compensator (DSSC) concept, which is to use multiple single-phase converters instead of one three-phase converter. Each converter within the DPFC is independent and has its own DC capacitor to provide the required DC voltage. The DPFC is derived from the Unified Power-Flow 
Controller (UPFC). The DPFC can be considered as a UPFC with an eliminated common dc link. The active power exchange between the shunt and series converters, which is through the common de link in the UPFC, is now through the transmission lines at the third-harmonic frequency.

\section{OPTIMAL LOCATION FOR DPFC}

In order to find the optimal location for the DPFC to be placed the bus which is mostly affected during faults has to be identified. With the increased loading of transmission and distribution lines, voltage instability problem has become a concern and serious issue for power system planners and operators. [9][10]The main challenge of this problem is to narrow down the locations where voltage instability could be initiated and to understand the origin of the problem. One effective way to narrow down the workspace is to identify weak buses in the systems, which are most likely to face voltage collapse and transmission line losses. [7][3].

\section{Voltage stability index:}

Consider a $n$-bus system having $1,2,3 \ldots n$, generator buses $(g)$, and $g+1, g+2 \ldots n$, the load buses $(r=n-g-$ $s)$. The transmission system can be represented by using a hybrid representation, by the following set of equations: [8]

$$
L_{\mathrm{j}}=\left|1-\sum_{i=1}^{g} F_{\mathrm{ij}} \frac{\left|V_{\mathrm{i}}\right|}{\left|V_{\mathrm{j}}\right|}\right|
$$

Where $\mathrm{j}=\mathrm{g}+1 \ldots \mathrm{n}$ and all the terms inside the sigma on the right hand side complex quantities. The complex values of $F_{i j}$ are obtained from the $Y_{B u s}$ matrix of power system. For a given operating condition:

$$
\left[\begin{array}{l}
I_{G} \\
I_{L}
\end{array}\right]=\left[\begin{array}{ll}
Y_{G G} & Y_{G L} \\
Y_{L G} & Y_{L L}
\end{array}\right]\left[\begin{array}{l}
V_{G} \\
V_{L}
\end{array}\right]
$$

Where $I_{G}, I_{L} \quad$ and $V_{G}, I_{L}$ represent complex current and voltage vectors at the generator nodes and load nodes $\left[Y_{G G}\right],\left[Y_{G L}\right],\left[Y_{L G}\right],\left[Y_{L L}\right]$ are corresponding partitioned portions of the $Y_{B u s}$ matrix.

This analysis will be carried out only for the load buses; hence the index obtained is for load buses only. For stability the index L must not be more than 1 for any of the nodes $j$. The global index for stability of the given power system is defined to be $\mathbf{L}=$ maximum of $\mathrm{L} \mathrm{j}$ for all $\mathrm{j}$ (load buses). The index far away from 1 and close to 0 indicates voltage stability. The L index will give the scalar number to each load bus. Among the various indices for voltage stability and voltage collapse prediction (i.e. far away from 1 and close to 1 or $>1$ respectively), the $\mathrm{L}$ index will give more accurate results. [4]

\section{FIREFLY OPTIMIZATION METHOD}

Firefly algorithm (FA), proposed by Xin-She Yang at Cambridge University. Firefly Algorithm [12, 13] is a metaheuristic, nature-inspired optimization algorithm which is based on the social flashing behavior of fireflies. The firefly algorithm [12] has three particular idealized rules which are based on some of the major flashing characteristics of real fireflies. The characteristics are as follows:

[1]. All fireflies are unisex and they will move towards more attractive and brighter ones regardless their sex.

[2]. The degree of attractiveness of a firefly is proportional to its brightness which decreases as the distance from the other firefly increases. This is due to the fact that the air absorbs light. If there is not a brighter one or more attractive firefly than a particular one, it will then move randomly.

[3]. The brightness or light intensity of a firefly is determined by the value of the objective function of a given problem. For maximization problems, the light intensity is proportional to the value of the objective function.

\subsection{Attractiveness}

In the firefly algorithm, the form of attractiveness function of a firefly is given by the following monotonically decreasing function:

$$
\beta(r)=\beta_{0} * \exp \left(-\gamma r^{m}\right), \quad m \geq 1
$$

Where, $\mathrm{r}$ is the distance between any two fireflies, $\beta_{0}$ is the initial attractiveness at $r=0$, and $\gamma$ is an absorption coefficient which controls the decrease of the light intensity.

\section{Distance}

The distance between any two fireflies $\mathrm{i}$ and $\mathrm{j}$ at positions $\mathrm{xi}$ and $\mathrm{xj}$ respectively can be defined as:

$$
r_{i j}=\left\|X_{i}-X_{j}\right\|=\sqrt{\left(\sum_{k=1}^{d} X_{i, k}-X_{j, k}\right)^{2}}
$$

Where $X_{i_{i} k}$ is the $k^{t h}$ component of the spatial coordinate $X_{i}$ of the $i^{\text {th }}$ firefly and $d$ is the number of dimensions.

\section{Movement}

The movement of a firefly $i$ which is attracted by a more attractive i.e., brighter firefly $\mathrm{j}$ is given by:

$$
\mathrm{V}_{\mathrm{i}(\text { new })}=\mathrm{V}_{\mathrm{i}(\mathrm{old})}+\beta_{0} * \exp \left(-\gamma \mathrm{r}_{\mathrm{ij}}{ }^{2}\right) *\left(\mathrm{X}_{\mathrm{i}}-\mathrm{X}_{\mathrm{j}}\right)+\alpha\left(\text { rand }-\frac{1}{2}\right)
$$

Where the first term is the current position of a firefly, the second term is used for considering a firefly's attractiveness to light intensity seen by adjacent fireflies and the third term is used for the random movement of a firefly in case there are no brighter ones. The coefficient $\alpha$ is a randomization parameter determined by the problem of interest, rand is a random number generator uniformly distributed in the space $[0,1]$. 


\section{FIREFLY ALGORITHM}

Step 1: Read the system data such as, Load bus values, Generator bus, slack bus and all other values.

Step 2: Initialize the parameters and constants of Firefly Algorithm. They are noff, $\alpha \max , \alpha \min , \beta 0, \gamma \min , \gamma \max$ and itermax (maximum number of iterations).

Step 3: Identify the candidate buses for placement of UPFC using L-index.

Step 4: Generate randomly ' $n$ ' number of fireflies. Where each fireflies between $\left(-V_{i \max }\right)$ and $\left(+V_{\text {imax }}\right)$. Each represented as rating of the device. Set iteration count to 1 .

Step 5: By placing all the n UPFC of each Firefly at the respective candidate locations and load flow analysis is performed to find the total real power loss $\left(P_{L}\right)$.The same procedure is repeated for the 'nop' number of particles to find the total real power losses. Fitness value corresponding to each particle is evaluated using the equation (6) for maximum loss reduction. Fitness function for maximum loss reduction is given by:

$F V=P_{L, \text { normal }}-P_{L, D P F C}$

Step 6: $P_{b e s t}$ values for all the fireflies are obtained from the fitness values and the best value among all the $P_{\text {best }}$ values ( $G$ best ) is identified.

Step 7: Error is calculated different between the Maximum fitness and average fitness values are is called the Error.

Error $=$ (maximum fitness - average fitness $)$

If this error is less than a specified tolerance then go to step 13.

Step 8: Determine the $\boldsymbol{r}_{i j}$ values of each firefly using the following equation:

$r_{i j}=G$ best $F V-P_{\text {best }} F V$

$\boldsymbol{r}_{i j}$ is obtained by finding the difference between the best fitness value $G$ best $\mathrm{FV}$ and $P_{\text {best }} \mathrm{FV}$ of the ith firefly.

Step 9: New $V_{i(\text { new })}$ values are calculated for all the fireflies using the following equation (5):

$\mathrm{V}_{\mathrm{i}(\text { new })}=\mathrm{V}_{\mathrm{i}(\text { old })}+\beta 0_{0} * \exp \left(-\gamma \mathrm{r}_{\mathrm{ij}}{ }^{2}\right) *\left(\mathrm{X}_{\mathrm{i}}-\mathrm{X}_{\mathrm{j}}\right)+\alpha\left(\right.$ rand $\left.-\frac{1}{2}\right)(8)$

Where, $\beta_{0}$ is the initial attractiveness $\gamma$ is the absorption coefficient rij is the difference between the best fitness value $G_{\text {best }}$ and fitness value FV of the ith firefly. $\alpha$ (iter) is the randomization parameter ( In this present work, $\alpha$ (iter) value is varied between 0.4 and 0.9 ).

Rand is the random number between 0 and 1 .

Step 10: Update the position of firefly by adding the velocity.

$P_{i, k+1}=P_{i, k}+V_{i(\text { new })}$

Step 11: New fitness values are calculated for the new positions of all the fireflies. If the new fitness value for any firefly is better than previous $P_{\text {best value then } P_{\text {best value }}}$ for that firefly is set to present fitness value. Similarly $G$ best value is identified from the latest $P_{\text {best values. }}$

Step 12: The iteration count is incremented and if iteration count is not reached maximum then go to step 3.

Step 13: $G$ best firefly gives the optimal UPFC sizes in $\mathrm{n}$ candidate locations and the results are printed.

Data used for Firefly: nop $=100 ; V_{\min }=-2.05$,
$V_{\max }=2.05, \gamma_{\max }=0.9, \gamma_{\min }=0.4, \beta_{0}=1, \mathrm{~T}=100$.

\section{GENETIC ALGORITHM}

Genetic Algorithm (GA) is one of the most famous metaheuristic optimization algorithms which is based on natural evolution and population. Genetics which is usually used to reach to a near global optimum solution. In each iteration of GA (referred as generation), a new set of string (i.e. chromosomes) with improved fitness is produced using genetic operators (i.e. selection, crossover and mutation) [5] [6].

\subsection{Selection}

In proposed GA, method of tournament selection is used for selection. This method chooses each parent by choosing (tournament size) players randomly and choosing the best individual out of that set to be a parent.

\subsection{Cross Over}

Cross over allows the genes from different parents to be combined in children by exchanging materials between two parents. Cross over function randomly selects a gene at the same coordinate from one of two parents and assign it to the child. For each chromosome, a random number is selected. If this number is between 0.01 and 0.3 , two parents are combined; else chromosome is transferred with no cross over. [9]

\subsection{Mutation}

GA creates mutation children by randomly changing the genes of individual parents. In this paper, GA adds a random vector from a Gaussian distribution to the parents. For each chromosome, random number is selected. If this number is between 0.01 and 0.1 , mutation process is applied; else chromosome is transferred with no mutation. [10]

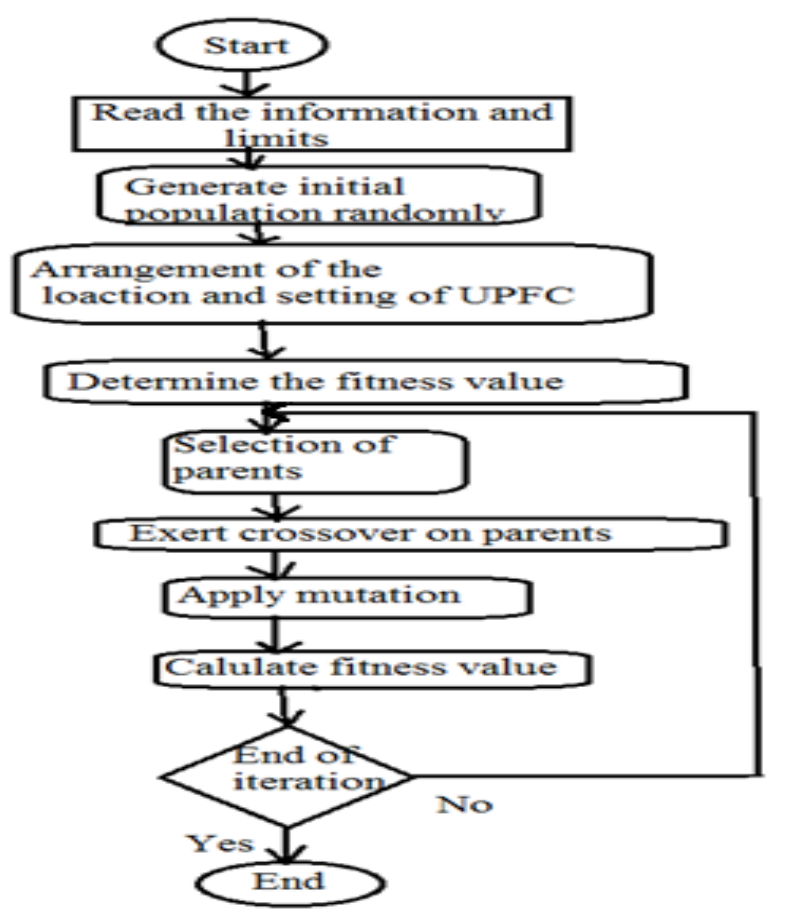

Fig.2: Genetic Algorithm flow chart 


\section{Data used for GA:}

Number of variables: 2, Length of variables: 2, Number of chromosomes: 30, Maximum number of generations: 300 .

\section{SIMULATION RESULTS}

\subsection{Results of 14 bus system:}

The proposed firefly algorithm is tested for IEEE-14 Bus systems. IEEE 14 bus system [14] contains 5 generator buses (bus numbers: 1,2,3,6 and 8), 9 load buses (bus numbers:4,5,7,9,10,11,12,13 and14) and 20 transmission lines. This test conducted for optimal location of DPFC on load buses, rating of DPFC and real power losses before and after placement DPFC for normal and $150 \%$ loading scenario using Firefly algorithm and compare Genetic algorithm shown in below.

Voltage stability index (L-index) gives weak buses like $9^{\text {th }}, 10^{\text {th }}, 14^{\text {th }}$ So DPFC placed in these buses.

Table 1: Total real power loss with and without DPFC in Genetic and Firefly Algorithm

\begin{tabular}{|c|c|c|c|c|c|c|}
\hline \multirow[b]{2}{*}{$\begin{array}{l}\text { Loss } \\
\text { Value }\end{array}$} & \multicolumn{2}{|c|}{ Normal load condition } & \multicolumn{2}{|c|}{$125 \%$ load condition } & \multicolumn{2}{|c|}{$150 \%$ load condition } \\
\hline & $\begin{array}{ll}\text { Before } & \text { DPFC } \\
\text { Real } & \text { power } \\
\text { losses } & \\
(\mathrm{M} . \mathrm{W}) & \\
\end{array}$ & $\begin{array}{l}\text { After } \\
\text { DPFC Real } \\
\text { power losses } \\
\text { (M.W) }\end{array}$ & $\begin{array}{ll}\text { Before } & \text { DPFC } \\
\text { Real } & \text { power } \\
\text { losses } & \\
(\mathrm{M} . \mathrm{W}) & \\
\end{array}$ & $\begin{array}{l}\text { After } \\
\text { DPFC Real } \\
\text { power losses } \\
\text { (M.W) }\end{array}$ & $\begin{array}{ll}\text { Before } & \text { DPFC } \\
\text { Real } & \text { power } \\
\text { losses } & \\
(\mathrm{M} . \mathrm{W}) & \\
\end{array}$ & $\begin{array}{l}\text { After } \\
\text { DPFC Real } \\
\text { power losses } \\
(\mathrm{M} . \mathrm{W})\end{array}$ \\
\hline $\begin{array}{l}\text { Total } \\
\text { Loss } \\
\text { (GA) } \\
\end{array}$ & 13.574 & 13.374 & 23.004 & 22.263 & 36.023 & 34.667 \\
\hline $\begin{array}{l}\text { Total } \\
\text { Loss } \\
\text { (FF) } \\
\end{array}$ & 13.575 & 13.377 & 23.004 & 22.218 & 36.023 & 33.723 \\
\hline
\end{tabular}

Table 1 shows the total real power loss with and without

DPFC in Genetic and Firefly algorithm.

Table 2: Total reactive power loss with and without DPFC in Genetic and Firefly Algorithm

\begin{tabular}{|c|c|c|c|c|c|c|c|c|}
\hline \multirow[b]{2}{*}{ Loss Value } & \multicolumn{3}{|c|}{ Normal load condition } & \multicolumn{3}{|c|}{$125 \%$ load condition } & \multicolumn{2}{|l|}{$150 \%$ load condition } \\
\hline & $\begin{array}{l}\text { Before } \\
\text { Real } \\
\text { losses } \\
\text { (M.W) }\end{array}$ & $\begin{array}{l}\text { DPFC } \\
\text { power }\end{array}$ & $\begin{array}{l}\text { After } \\
\text { DPFC Real } \\
\text { power losses } \\
\text { (M.W) }\end{array}$ & $\begin{array}{l}\text { Before } \\
\text { Real } \\
\text { losses } \\
\text { (M.W) }\end{array}$ & $\begin{array}{l}\text { DPFC } \\
\text { power }\end{array}$ & $\begin{array}{l}\text { After } \\
\text { DPFC Real } \\
\text { power losses } \\
\text { (M.W) }\end{array}$ & $\begin{array}{l}\text { Before DPFC Real } \\
\text { power losses } \\
(\mathrm{M} . \mathrm{W})\end{array}$ & $\begin{array}{l}\text { After } \\
\text { DPFC Real } \\
\text { power losses } \\
(\mathrm{M} . \mathrm{W})\end{array}$ \\
\hline $\begin{array}{ll}\text { Total } & \text { Loss } \\
\text { (GA) } & \end{array}$ & 28.541 & & 28.151 & 67.621 & & 64.541 & 120.772 & 115.615 \\
\hline $\begin{array}{l}\text { Total Loss } \\
\text { (FF) }\end{array}$ & 28.541 & & 27.931 & 67.621 & & 63.217 & 120.772 & 108.806 \\
\hline
\end{tabular}

Table 2 shows the total reactive power loss with and without DPFC in Genetic and Firefly algorithm.

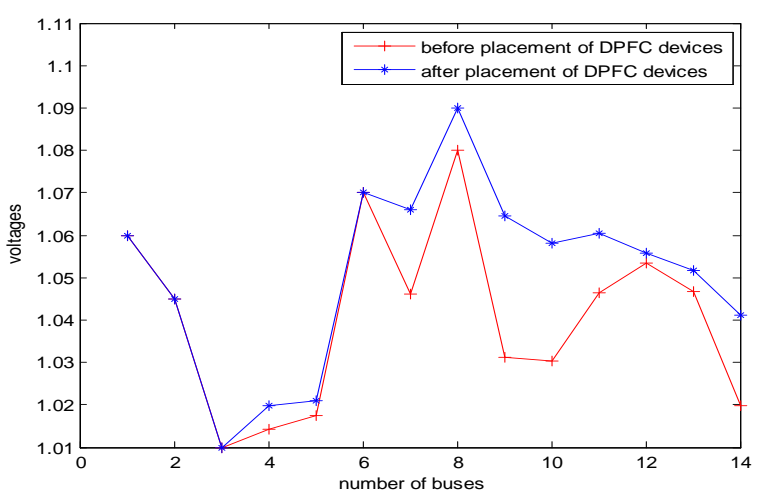

Fig.3: Voltage profile before and after placement of DPFC Normal load in GA
Simulation Results for normal, $125 \%$ and $150 \%$ load conditions with and without DPFC in Genetic Algorithm as shown in the Fig.3, Fig.4 and Fig.5.

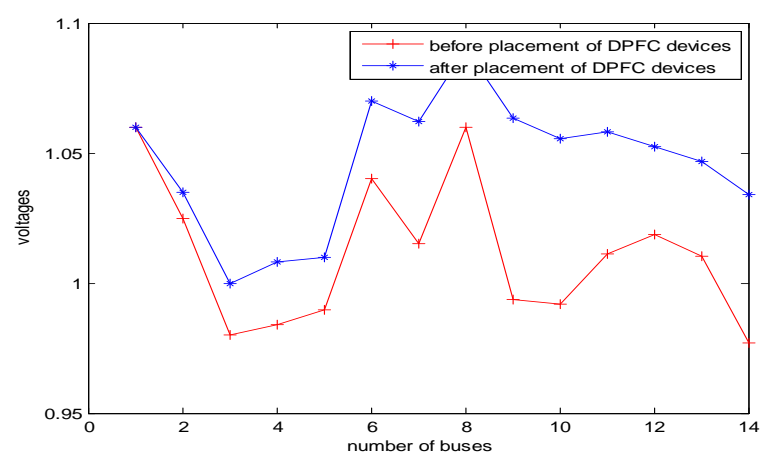

Fig.4: Voltage profile before and after placement of DPFC for $125 \%$ load in GA 


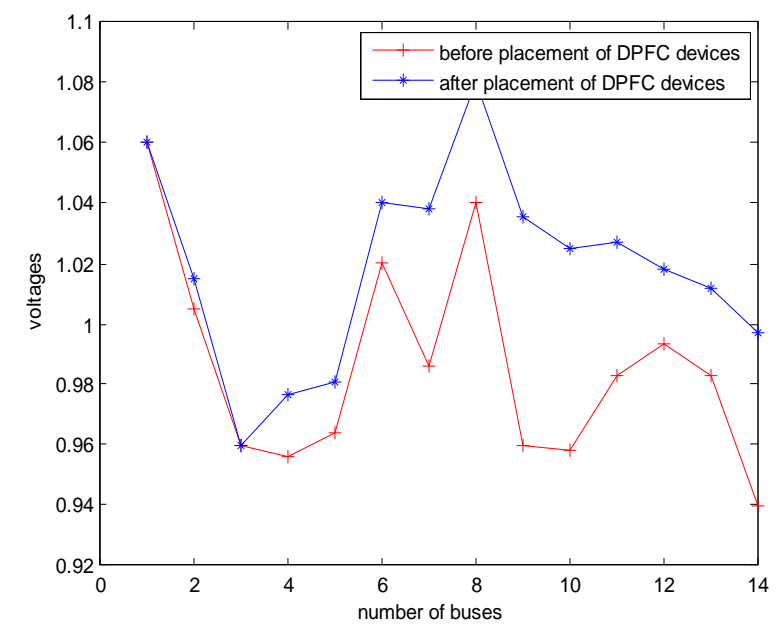

Fig.5: Voltage profile before and after placement of DPFC for $150 \%$ load in GA

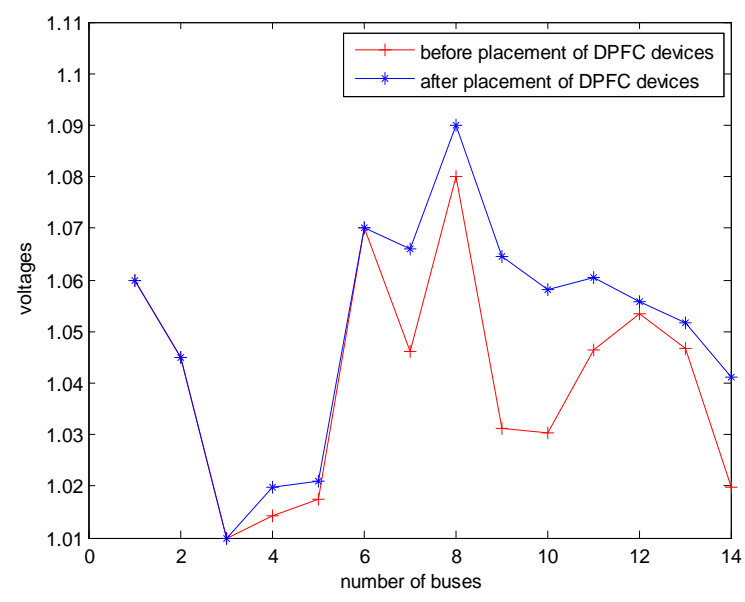

Fig.6: Voltage profile before and after placement of DPFC for normal load in FA

Simulation Results for normal, $125 \%$ and $150 \%$ load conditions with and without DPFC in Firefly Algorithm as shown in Fig.6, Fig.7 and Fig.8.

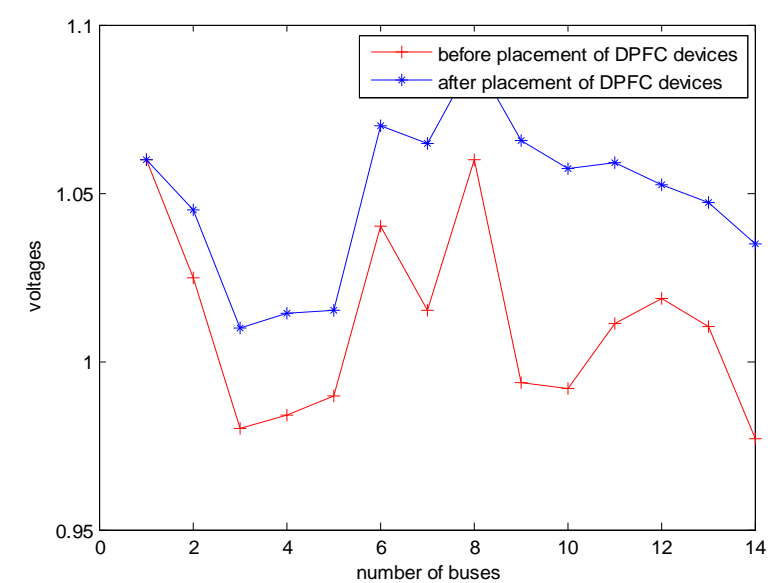

Fig.7: Voltage profile before and after placement of DPFC for $125 \%$ load in FA

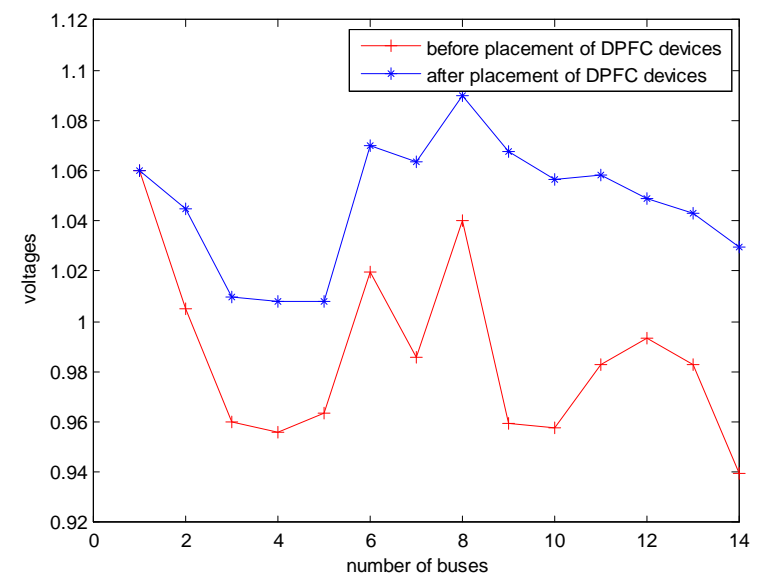

Fig.8: Voltage profile before and after placement of DPFC for $150 \%$ load in FA.

\subsection{Results of 30 bus system:}

IEEE 30 bus system[14] contains 6 generator buses (bus numbers: 1, 2, $5,8,11$, and 13), 24 load buses (bus numbers : 3, 4, 6, 7, 9, 10, 12, 14 ,15, 16, 17, 18, 19, 20, 21, 22, 23, $24,25,26,27,28,29$ and 30) and 41 transmission lines. DPFC is placed in optimal location on load buses, rating of DPFC and real power losses after DPFC placement for normal $125 \%$ and $150 \%$ loading scenario using Firefly algorithm and comparing with Genetic algorithm is shown.

Table 3: Total real power loss with and without DPFC in Genetic and Firefly Algorithm

\begin{tabular}{|c|c|c|c|c|c|c|}
\hline \multirow[b]{2}{*}{$\begin{array}{l}\text { Loss } \\
\text { Valu } \\
\text { e }\end{array}$} & \multicolumn{2}{|c|}{$\begin{array}{l}\text { Normal load } \\
\text { condition }\end{array}$} & \multicolumn{2}{|c|}{$\begin{array}{l}125 \% \text { load } \\
\text { condition }\end{array}$} & \multicolumn{2}{|c|}{$\begin{array}{ll}150 \% \text { load } \\
\text { condition }\end{array}$} \\
\hline & $\begin{array}{l}\text { Befor } \\
\text { e } \\
\text { DPF } \\
\text { C } \\
\text { Real } \\
\text { powe } \\
\text { r } \\
\text { losse } \\
\text { s } \\
\text { (M. } \\
\text { W) } \\
\end{array}$ & $\begin{array}{l}\text { After } \\
\text { DPF } \\
\text { C } \\
\text { Real } \\
\text { powe } \\
\text { r } \\
\text { losse } \\
\text { s } \\
\text { (M. } \\
\text { W) }\end{array}$ & $\begin{array}{l}\text { Befor } \\
\text { e } \\
\text { DPF } \\
\text { C } \\
\text { Real } \\
\text { powe } \\
\text { r } \\
\text { losse } \\
\text { s } \\
\text { (M. } \\
\text { W) } \\
\end{array}$ & $\begin{array}{l}\text { After } \\
\text { DPF } \\
\text { C } \\
\text { Real } \\
\text { powe } \\
\text { r } \\
\text { losse } \\
\text { s } \\
\text { (M. } \\
\text { W) }\end{array}$ & $\begin{array}{l}\text { Befor } \\
\text { e } \\
\text { DPF } \\
\text { C } \\
\text { Real } \\
\text { powe } \\
\text { r } \\
\text { losse } \\
\text { s } \\
(\mathrm{M} . \\
\text { W) } \\
\end{array}$ & $\begin{array}{l}\text { After } \\
\text { DPFC } \\
\text { Real } \\
\text { power } \\
\text { losses } \\
\text { (M.W) }\end{array}$ \\
\hline $\begin{array}{l}\text { Tota } \\
\text { l } \\
\text { Loss } \\
\text { (GA } \\
\text { ) }\end{array}$ & $\begin{array}{l}17.52 \\
3\end{array}$ & $\begin{array}{l}17.47 \\
2\end{array}$ & $\begin{array}{l}29.84 \\
2\end{array}$ & $\begin{array}{l}29.64 \\
3\end{array}$ & $\begin{array}{l}46.93 \\
2\end{array}$ & $\begin{array}{l}47.702 \\
4\end{array}$ \\
\hline $\begin{array}{l}\text { Tota } \\
\text { l } \\
\text { Loss } \\
\text { (FF) }\end{array}$ & $\begin{array}{l}17.52 \\
3\end{array}$ & $\begin{array}{l}17.47 \\
1\end{array}$ & $\begin{array}{l}29.84 \\
2\end{array}$ & $\begin{array}{l}29.15 \\
4\end{array}$ & $\begin{array}{l}46.93 \\
2\end{array}$ & 44.553 \\
\hline
\end{tabular}

Table 3 shows the total real power loss with and without DPFC in Genetic and Firefly algorithm.

Table 4: Total reactive power loss with and without DPFC in Genetic and Firefly Algorithm

\begin{tabular}{|l|l|l|ll|}
\hline Loss & $\begin{array}{l}\text { Normal load } \\
\text { Valu }\end{array}$ & $\begin{array}{l}125 \% \text { load } \\
\text { condition }\end{array}$ & $\begin{array}{l}150 \% \text { load } \\
\text { condition }\end{array}$ & \begin{tabular}{l} 
condition \\
\hline
\end{tabular} \\
\hline
\end{tabular}




\begin{tabular}{|c|c|c|c|c|c|c|}
\hline $\mathrm{e}$ & $\begin{array}{l}\text { Befor } \\
\text { e } \\
\text { DPFC } \\
\text { Real } \\
\text { power } \\
\text { losses } \\
\text { (M.W } \\
\text { ) }\end{array}$ & $\begin{array}{l}\text { After } \\
\text { DPFC } \\
\text { Real } \\
\text { power } \\
\text { losses } \\
\text { (M.W } \\
\text { ) }\end{array}$ & $\begin{array}{l}\text { Befor } \\
\text { e } \\
\text { DPFC } \\
\text { Real } \\
\text { power } \\
\text { losses } \\
\text { (M.W } \\
\text { ) }\end{array}$ & $\begin{array}{l}\text { After } \\
\text { DPFC } \\
\text { Real } \\
\text { power } \\
\text { losses } \\
\text { (M.W } \\
\text { ) }\end{array}$ & $\begin{array}{l}\text { Before } \\
\text { DPFC } \\
\text { Real } \\
\text { power } \\
\text { losses } \\
\text { (M.W) }\end{array}$ & $\begin{array}{l}\text { After } \\
\text { DPFC } \\
\text { Real } \\
\text { power } \\
\text { losses } \\
\text { (M.W) }\end{array}$ \\
\hline $\begin{array}{l}\text { Tota } \\
\text { I } \\
\text { Loss } \\
\text { (GA) }\end{array}$ & $\begin{array}{l}22.18 \\
5\end{array}$ & $\begin{array}{l}22.16 \\
6\end{array}$ & $\begin{array}{l}72.56 \\
3\end{array}$ & $\begin{array}{l}72.49 \\
9\end{array}$ & $\begin{array}{l}138.78 \\
1\end{array}$ & $\begin{array}{l}142.95 \\
1\end{array}$ \\
\hline $\begin{array}{l}\text { Tota } \\
1 \\
\text { Loss } \\
\text { (FF) }\end{array}$ & $\begin{array}{l}22.18 \\
5\end{array}$ & $\begin{array}{l}22.18 \\
2\end{array}$ & $\begin{array}{l}72.56 \\
3\end{array}$ & $\begin{array}{l}66.05 \\
8\end{array}$ & $\begin{array}{l}138.78 \\
1\end{array}$ & $\begin{array}{l}123.88 \\
4\end{array}$ \\
\hline
\end{tabular}

Table 4 shows the total reactive power loss with and without DPFC in Genetic and Firefly algorithm.

Simulation Results for normal, $125 \%$ and $150 \%$ load conditions with and without DPFC in Genetic Algorithm as shown in Fig.9, Fig.10 and Fig.11.

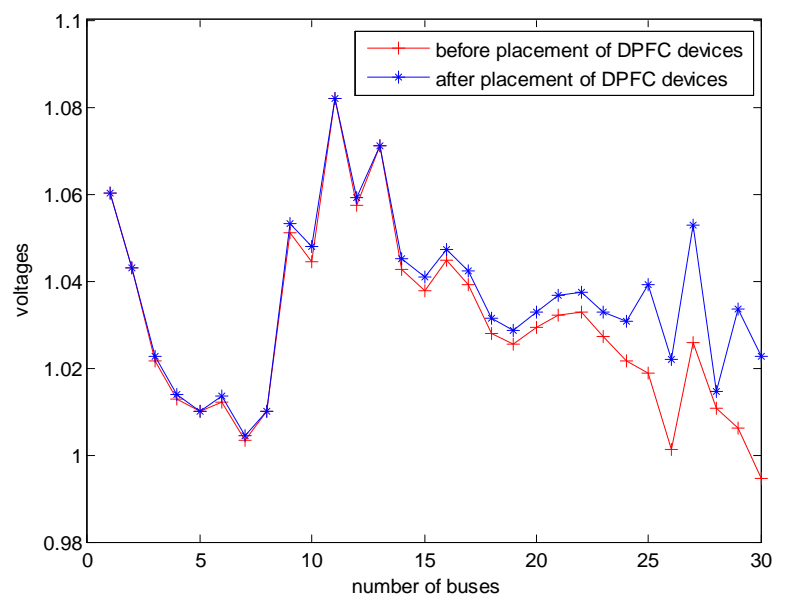

Fig.9: Voltage profile before and after placement of DPFC Normal load in GA

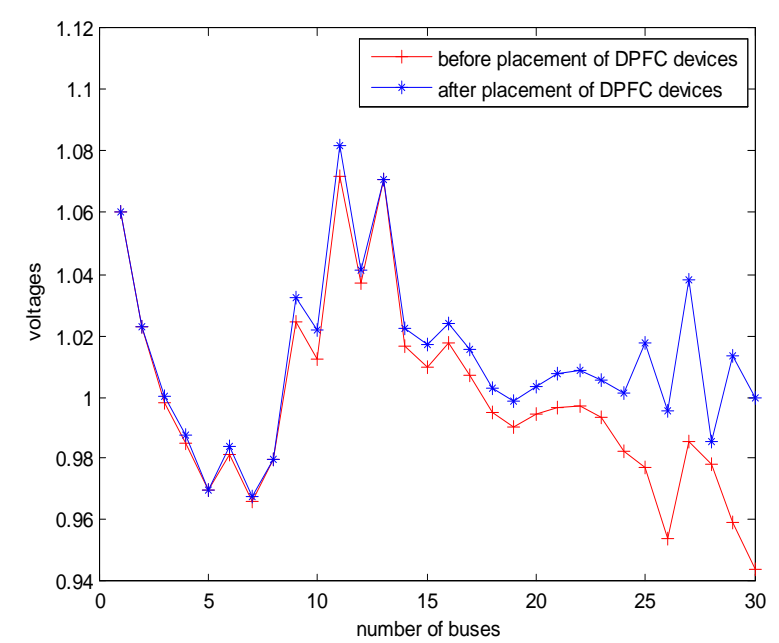

Fig.10: Voltage profile before and after placement of DPFC for $125 \%$ load in GA

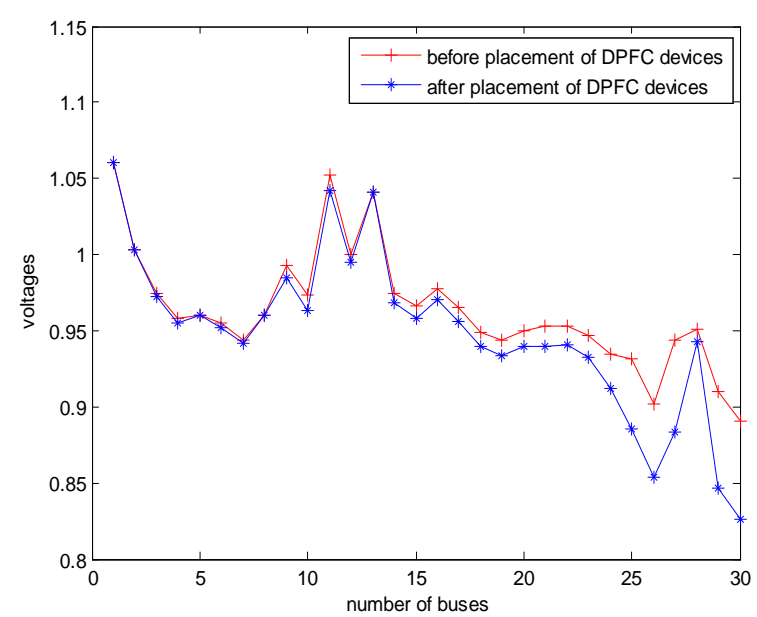

Fig.11: Voltage profile before and after placement of DPFC for $150 \%$ load in GA

Simulation Results for normal, $125 \%$ and $150 \%$ load conditions with and without DPFC in Genetic Algorithm as shown in Fig.12, Fig.13 and Fig.14.

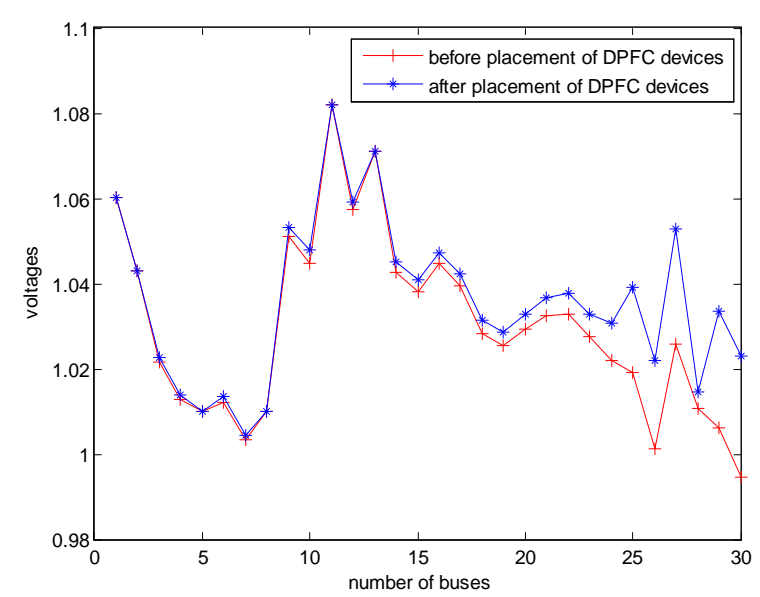

Fig.12: Voltage profile before and after placement of DPFC for normal load in FA

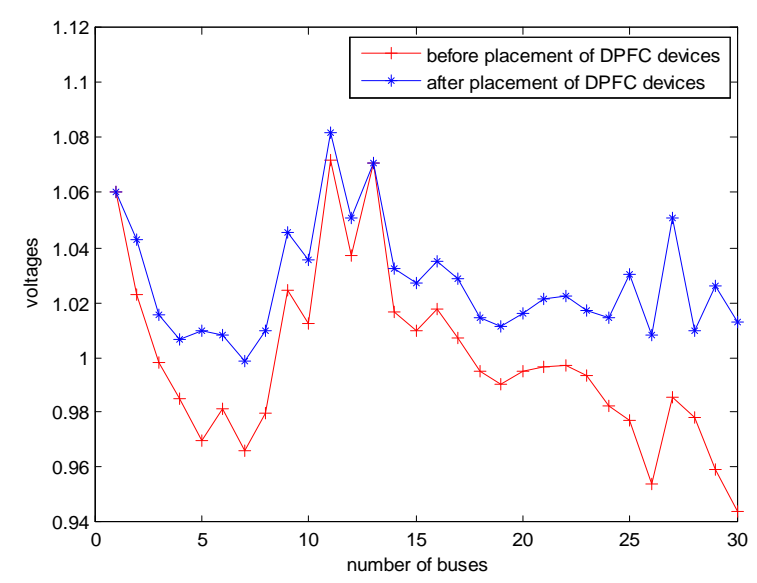

Fig.13: Voltage profile before and after placement of DPFC for $125 \%$ load in FA 


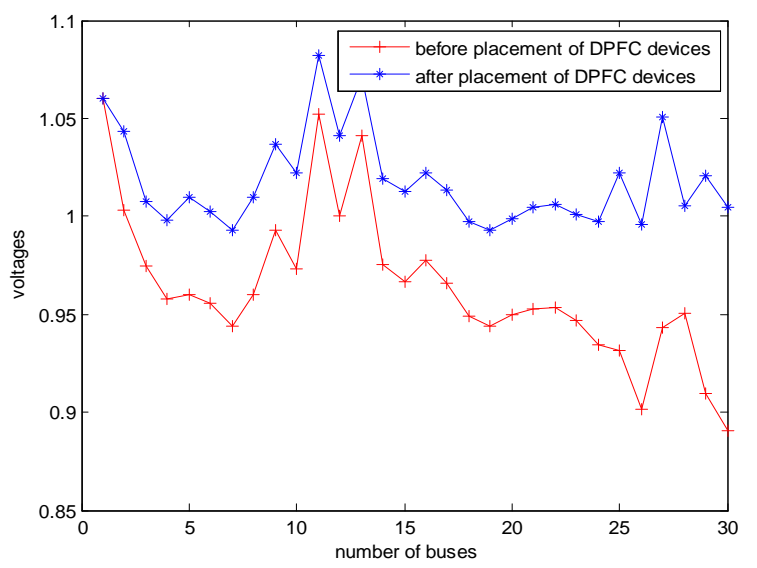

Fig.14: Voltage profile before and after placement of DPFC for $150 \%$ load in FA

\section{CONCLUSION:}

In this paper, a two-stage methodology of finding the optimal location and sizes of Unified Power Flow Controller for Real and Reactive power compensation of standard tested IEEE-14 and IEEE-30 Bus system is presented. Voltage stability index approach is proposed to find the optimal Distributed Power Flow Controller locations and firefly and Genetic algorithms is proposed to find the optimal sizes of Distributed Power Flow Controller. Based on the simulation results, the following conclusions are drawn: By installing Distributed Power Flow Controller at all the potential locations, the total real and reactive power loss of the system has been reduced significantly and at same bus voltages are improved substantially. The proposed Firefly optimization iteratively searches the optimal Distributed Power Flow Controller size for improve the voltage values reduced power losses more compare to the Genetic Algorithm. The coding of Firefly method is simple compare to the GA. Because the Firefly method has no evolution operators such as cross over and mutation, which appears in GA method.

\section{REFERENCES}

[1]. N. G. Hingorani and L. Gyugyi, "Understanding FACTS: Concepts and Technology of Flexible AC Transmission Systems", New York: IEEE Press, (2000).

[2]. Zhihui Yuan, Sjoerd W.H. de Haan, Jan Braham Ferreira, and Dalibor Cvoric. "A FACTS Device: Distributed Power-Flow Controller (DPFC)" IEEE Transactions on Power Electronics, VOL.25, NO.10, October 2010: PP: 2564-2572.

[3]. T.Nireekshana, Dr.G.Kesava Rao, Dr.S.Siva Naga Raju "Incorporation of Unified Power Flow Controller Model for Optimal Placement using Particle Swam Optimization Techniquel, 978-1-4244-8679-3/11/2011 IEEE.

[4]. C.R.Fuerte-Esquivel, E.Acha, "Unified power flow controller: a critical comparison of Newton-Raphson UPFC algorithms in power flow studies" IEEE Proceedings on Generation, Transmission, Distribution, Vol. 144, No. 5, pp. 437-443, Sept 1997.
[5]. k. Venkateswarlu, 2ch. Saibabu," A New Evolutionary Algorithms Used For Optimal Location Of Upfc On Power System “,(C) 2005 - 2010 Jatit \& Lls. All Rights Reserved.

[6]. Jigar S.Sarda1, Manish J. Chauhan, Viren B. Pandya, Dhaval G. Patel4, "Optimal Location Of Multi-Types Of Facts Devices Using Genetic Algorithm", International Journal Of Research In Computer Science Eissn 2249-8265 Volume 2 Issue 3 (2012) Pp. 11-15.

[7]. Sreekanth Reddy Donapati and M.K.Verma ,"An Approach for Optimal Placement of UPFC to Enhance Voltage Stability Margin under Contingenciesl, Fifteenth National Power Systems Conference (NPSC), IIT Bombay, December 2008.

[8]. Kiran Kumar Kuthadi and 2 M. Suresh Babu , ”A Modified Particle Swarm Optimization Technique Forsolving Improvement Of Voltage Stability And Reduce Power Losses Using Upfc”, Issn: 2248-9622, Vol. 2, Issue 3, May-Jun 2012, Pp. 1516-1521.

[9]. M.Behshad A.Lashkarara A. H. Rahmani "Optimal Location of UPFC Device Considering System Laudability, Total Fuel cost, Power losses and Cost of Installation", 2009 2nd International Conference on Power Electronics and Intelligent Transportation System.

[10]. R.Jahani H.A.Shayanfar N.M.Tabatabaei J. Olamaei, "Optimal placement of UPFC power system by a New advanced Heuristic method", International Journal on - Technical and Physical Problems of Engineering, ISSN 2077-3528, December 2010.

[11]. Bindeshwar Singh, N. K. Sharma and A. N. Tiwari, and S.P.Singh "Incorporation of FACTS Controllers in Newton Raphson Load Flow for Power Flow Operation" Bindeshwar Singh et. al. / (IJCSE) International Journal on Computer Science and Engineering Vol. 02, No. 06, 2010, 2117-2124,

[12]. Xin-She Yang," Firefly Algorithms for Multimodal Optimization", Xiv: 1003.1466v1 [math.OC] 7 Mar 2010.

[13]. K..Sudhakara Reddy, Dr. M. Damodara Reddy,"Economic Load Dispatch Using Firefly Algorithm", International Journal of Engineering Research and Applications ISSN: 2248-9622 Vol. 2, Issue4, July-August 2012, pp.2325-2330.

[14]. IEEE 14-bus test system data [Online]. Available: http://www.ee.washington.edu/research/pstca/pf14/pg tca14bus.htm. 